레터논문 (Letter Paper)

방송공학회논문지 제19권 제2호, 2014년 3월 (JBE Vol. 19, No. 2, March 2014)

http://dx.doi.org/10.5909/JBE.2014.19.2.268

ISSN 2287-9137 (Online) ISSN 1226-7953 (Print)

\title{
최적의 $\mathrm{FEC}$ 부호율 결정을 위한 정확한 채널손실 한계집합 추정기법
}

\author{
정 태 준 ${ }^{a}$, 정 요 원 ${ }^{b}$, 서 광 덕 ${ }^{\natural}$
}

\section{An Accurate Estimation of Channel Loss Threshold Set for Optimal FEC Code Rate Decision}

\author{
Tae-jun Jung ${ }^{\text {a)}}$, Yo-won Jeong ${ }^{\text {b) }}$, and Kwang-deok Seo ${ }^{\text {a) }}$ \\ 요 약
}

소스 부호 왜곡 모델 및 채널 유도 왜곡 모델 기반의 기존의 $\mathrm{FEC}$ 부호율 결정 기법들은 일반적으로 높은 계산 복잡도와 구현 비용 을 요구하는 모델 파라메터 트레이닝 과정을 요구한다. 본 논문에서는 복잡한 모델링 과정을 피하기 위해서 최적의 FEC 부호율 결정 을 위한 채널 손실 한계집합을 추정하기 위한 정확한 소스-채널 결합 왜곡 모델을 제안한다.

\begin{abstract}
Conventional forward error correction (FEC) code rate decision schemes using analytical source coding distortion model and channel-induced distortion model are usually complex, and require the typical process of model parameter training which involves potentially high computational complexity and implementation cost. To avoid the complex modeling procedure, we propose a simple but accurate joint source-channel distortion model to estimate channel loss threshold set for optimal FEC code rate decision.
\end{abstract}

Keywords: code rate decision, forward error correction, channel loss threshold set

\section{Introduction}

When transporting video over the wireline/wireless chan-

a) 연세대학교 (Yonsei University)

b) 삼성전자 (Samsung Electronics Corporation)

₹ Corresponding Author : 서광덕(Kwang-deok Seo) E-mail:kdseo@yonsei.ac.kr Tel: +82-33-760-2788

※This research was supported by the MSIP (Ministry of Science, ICT \& Future Planning), Korea, under the "ITRC (Information Technology Research Center)" support program (NIPA-2014-H0301-14-1012) supervised by the NIPA (National IT Industry Promotion Agency). - Manuscript received October 17, 2013 Revised February 21, 2014 Accepted February 21, 2014 nel, each video packet can be received correctly, received with errors, or lost by the network. It is necessary for the video sender to provide adequate error resilience features. It is efficient to adaptively change the FEC code rate in response to time-varying packet loss dynamics in order to ensure consistent optimal video quality [1]. The optimal FEC code rate decision is a crucial procedure to determine the optimal source and channel coding rates to minimize the overall picture distortion when transporting video packets over packet loss channels. Several previous studies have 
focused on the optimal code rate decision for joint source channel coding (JSCC). In [2], a source coding distortion model and a channel-induced distortion model were proposed as a means of determining a combination of the optimal intra-refresh rate and code rate. Similarly, Frossard et al. [3] proposed an end-to-end distortion model, in which channel-induced distortion was assumed to be proportional to the number of lost pixels. Their modeling equations are very complex and include numerous modeling parameters. Kwon et al. [4] proposed a practical method based on an observation that the residual packet loss probability in the optimal code rate stays near to a constant value. However, actually this residual packet loss probability is not constant any more at the high channel packet loss probabilities.

In this paper, we propose an accurate estimation of channel loss threshold set for optimal code rate decision.

\section{Video Transmission System and Channel Model}

The fundamental structure of the video transmissionsystem that supports both source and channel codings is presented in Fig. 1. The system consists of a video encoder/decoder, a channel encoder/decoder, and rate allocation block. The rate allocation block optimizes the video

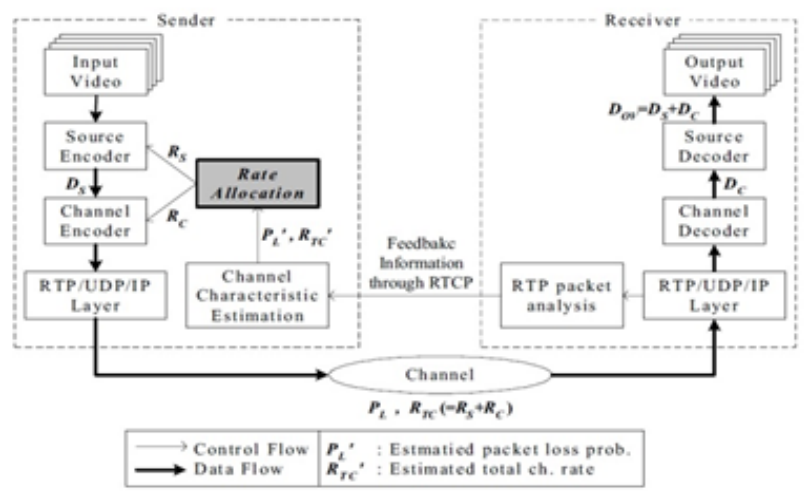

그림 1. 비디오 전송 시스템의 기본 구조

Fig. 1. Fundamental structure of the video transmission system quality for a given channel condition. The sender periodically receives information about the instantaneous channel status from the receiver through a RTCP feedback report. From this information, the block for the channel characteristic estimation calculates the current status of the channel packet loss rate, $P_{L}$, and the available total transmission rate, $R_{T C}$. The channel encoder in Fig. 1 generates $n$ FEC packets for every $k$ video packets by the RS code, denoted as $\mathrm{RS}(n, k)$. The code rate of $\mathrm{RS}$ code is defined as

$$
r=k / n
$$

Let $R_{S}$ and $R_{C}$ be the source and channel coding bit rates. When we define the total transmission rate by $R_{T C}$, then $R_{S}$ and $R_{C}$ can be expressed as

$$
R_{S}=R_{T C} \cdot r, \quad R_{C}=R_{T C} \cdot(1-r) .
$$

For an $R S(n, k)$ code, lost packets up to $\mathrm{n}-\mathrm{k}$ packets in a transmission group can be completely recovered [3]. However, if more than $n-k$ packets are lost, this transmission group cannot be recovered in its entirety. The residual packet loss probability is defined as the probability that a video packet is lost but cannot be correctly recovered even by the channel decoding. The residual packet loss probability denoted as $P_{R}$ depends on $r$ and $P_{L}$, and can be represented as [2]

$$
P_{R}\left(r, P_{L}\right)=\sum_{i=n-k+1}^{n}\left(\begin{array}{l}
n \\
i
\end{array}\right) p_{L}^{i}\left(1-p_{L}\right)^{n-i}
$$

The overall distortion $\left(D_{O V}\right)$ of the reconstructed video depends upon both the source coding distortion $\left(D_{S}\right)$ and channel induced distortion $\left(D_{C}\right)$. We can also express the optimal code rate decision with respect to minimizing the overall distortion for the given $n$ as follows:

$$
r^{*}=\arg \min _{r}\left\{D_{o v}\left(r, P_{L}\right) \mid n\right\} .
$$




\section{Channel Loss Threshold Set}

In this section, we introduce two types of loss threshold sets, the channel loss threshold set and the residual loss threshold set. We employed an H.264/AVC source coder and combined it with $R S(5, k)(k=1,2, \cdots, 5)$ channel coder using $\mathrm{R}_{\mathrm{TC}}=100$ Kbps. Since we can adjust $r$ by changing $k$ and fixing $n$ as $n_{0}, r$ can be redefined as follows:

$$
r_{k}=k / n_{0}, \quad k=1,2, \ldots, n_{0} .
$$

In Fig. 2, we can see that though $P_{L}$ increases, PSNR $\left(r_{k}, P_{L}\right)$ barely decreases in the ranges of low $P_{L}$ where almost all lost packets are recovered by the channel decoder. The optimal code rate can be classified as follows:

$$
r^{*}= \begin{cases}r_{5}, & P_{L} \leq 0.006 \\ r_{4} & 0.006<P_{L}<0.08 \\ r_{3} & 0.08<P_{L} \leq 0.2 \\ r_{2} & 0.2<P_{L}<0.45 \\ r_{1} & 0.45<P_{L} .\end{cases}
$$

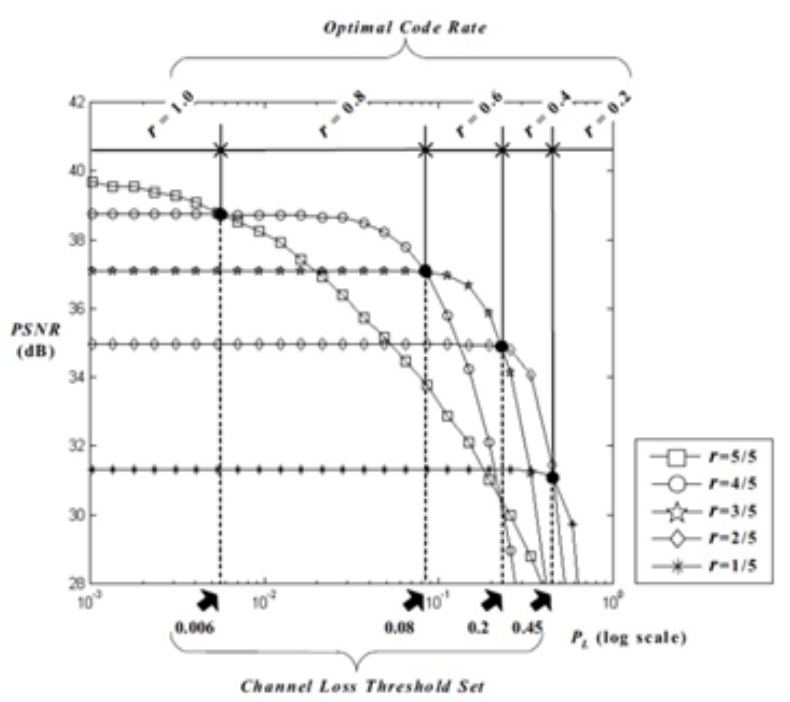

그림 2. 다양한 패킷손실 조건에서 Akiyo 시퀀스에 대한 최적의 부호율 결정 을 위한 PSNR 곡선

Fig. 2. PSNR curves for determining optimum code rates in various packet loss channel condition for Akiyo sequence
We call the set of $P_{L}$ values which correspond to the threshold boundary to change the code rate a channel loss threshold set (CLTS). The CLTS is represented as

$$
=\left\{\begin{array}{c}
C L T S \\
P_{L K} \mid P_{L} \text { val.of } \operatorname{PSNR}\left(r_{k}, P_{L}\right)=\operatorname{PSNR}\left(r_{k-1}, P_{L}\right), \\
k=2,3, \ldots, n_{0}
\end{array}\right\}
$$

To get the CLTS quickly and accurately, we introduce another loss threshold set called residual loss threshold set (RLTS). We define the RLTS as

$$
R L T S=\left\{P_{R K} \mid P_{R K}=P_{R}\left(r_{k}, P_{L K}\right), k=2,3, \ldots, n_{0}\right\},
$$

in which each element of RLTS, $P_{R K}$, is the value shown in (3) for the given $r_{k}$ and $P_{L K}$.

\section{Joint Source-channel Distortion Model}

If we use MSE as a distortion measure, we could observe that the difference of source distortion between $r_{k}$ and $r_{k-1}$ is likely equal to the channel distortion measured at $r=r_{k}$ and $P_{L}=P_{L k}$. We can formulate this observation as

$$
D\left(r_{k-1}, 0\right)-D\left(r_{k}, 0\right) \approx D_{c}\left(r_{k}, P_{L k}\right), k=2,3, \ldots, n_{0},
$$

where $D_{C}\left(r_{k}, P_{L k}\right)$ means the channel distortion.

The $D\left(r_{k}, 0\right)$ can be represented as

$$
D\left(r_{k}, 0\right)=\frac{\theta}{R_{T C_{k}}-R_{0}}+D_{0}, k=2,3, \ldots, n_{0},
$$

where $\left(\theta, R_{0}, D_{0}\right)$ are the parameters of the model which depend on the encoded video sequence [2].

Fig. 3 shows that the distortion of the received video is linearly proportional to the residual packet loss probability. Therefore, by using (3), we can represent $D_{C}\left(r_{k}, P_{L k}\right)$ as

$$
D_{c}\left(r_{k}, P_{L k}\right)=D_{c}\left(r_{k}, P_{R k}\right)=b P_{R k}, k=2,3, \ldots, n_{0}
$$


where $b$ is a proportional constant. If we substitute (5), (10), and (11) into (9), we can obtain $P_{R k}$ expressed as

$$
\begin{aligned}
& P_{R k}=\frac{\beta}{(k-(\alpha+1))(k-\alpha)}, \\
& \alpha=\frac{R_{0} n_{0}}{R_{T C}}, \beta=\frac{\theta n_{0}}{b R_{T c}}, k=2,3, \ldots n_{0}
\end{aligned}
$$

where $\alpha$ and $\beta$ are the model parameters. By using (12), we can get all elements of the RLTS defined in (8), and then the corresponding CLTS can be obtained from (3).
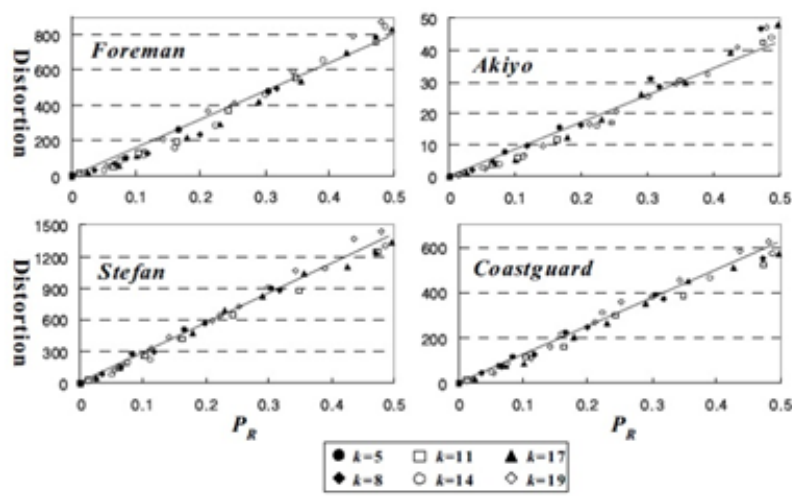

그림 3. $n_{0}=20$ 일 때 $k$ 값에 대한 잔여패킷 손실확률에 대비한 비디오 왜곡 Fig. 3. Video distortion versus residual packet loss probability PRkfor various $k$ where $n_{0}=20$

\section{Performance Evaluation}

To evaluate the accuracy of the estimated CLTS using the joint source-channel distortion model, we performed simulations using H.264/AVC codec. The $\mathrm{n}_{0}$ is fixed to be 20. We evaluate the PSNR performance of the code rates estimated by the proposed method, and compare it with the optimal code rate case when the packet loss ratio varies from 0.001 to 0.2 . Table 1 compares the average PSNR performance. It can be seen that the PSNR performance obtained by the proposed method is very close to the optimal PSNR performance. The PSNR gap between the two approaches is just within $0.5 \mathrm{~dB}$. Fig.4 demonstrates the
PSNR performance for various packet loss rates, in which the Soccer sequenceis used.

표 1. 제안된 방법에 의해 추정된 부호율과 실제 최적의 부호율 간의 평균 PSNR 성능비교

Table 1. Comparison of the average PSNR between using real optimal code rates and using code rates estimated by the proposed method

\begin{tabular}{lcccc}
\hline & Foreman & Akiyo & Stefan & Coastguard \\
\hline \hline $\begin{array}{l}\text { Optimal } \\
\text { code rate }\end{array}$ & $31.11 \mathrm{~dB}$ & $32.83 \mathrm{~dB}$ & $\mathbf{3 0 . 1 7} \mathrm{dB}$ & $\mathbf{3 1 . 4 5} \mathrm{dB}$ \\
\hline $\begin{array}{l}\text { Estimated } \\
\text { code rate }\end{array}$ & $30.89 \mathrm{~dB}$ & $32.53 \mathrm{~dB}$ & $29.85 \mathrm{~dB}$ & $\mathbf{3 1 . 1 2 \mathrm { dB }}$ \\
\hline
\end{tabular}

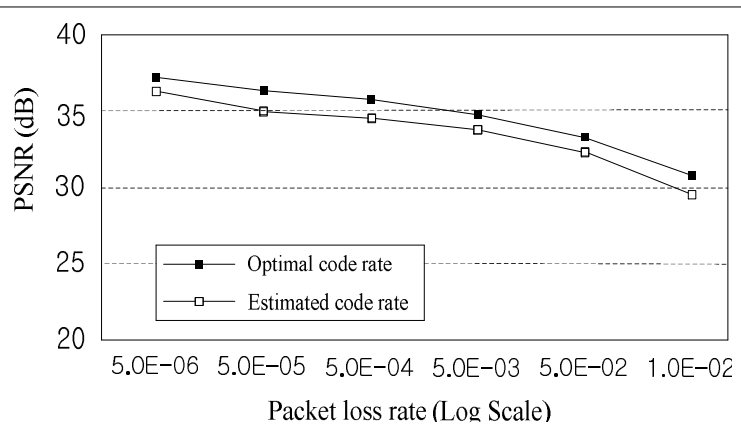

그림 4. Soccer 시퀀스에 대한 PSNR 성능 비교.

Fig. 4. Comparison of PSNR performance for Soccer sequence

\section{Conclusions}

In this paper, we proposed an accurate estimation of channel loss threshold set for optimal FEC code rate decision.

\section{References}

[1] M. Azni et al., "Joint source and channel coding for real time H.264 coded video transmission using mobile hand-held devices," IETE J. of Research, vol. 55, no. 4, Aug. 2009, pp. 154-161.

[2] K. Stuhlmuller, N. Farber, and B. Girod, "Analysis of video transmission over lossy channels," IEEE J. Sel. Areas in Commun., vol. 18, no. 6, Jun. 2000, pp. 1012-1032.

[3] P. Frossard and O. Verscheure, "Joint source/FEC rate selection for quality-optimal MPEG-2 video delivery," IEEE Trans. Image Process., vol. 10, no. 12, Dec. 2001, pp.1815-1824.

[4] J. Kwon and J. Kim, "Adaptive code rate decision of joint source-channel coding for wireless video," Electron. Lett., vol. 38, no. 25, Dec. 2002, pp. 1752-1753. 